\title{
Um Debate Sobre o Fenômeno do Populismo na Europa Central Pós
}

1989

Flávio Rodriguês Barbosa

\section{Flávio Rodriguês Barbosa}

Doutor em Ciências Sociais pelo

PPGCSO da Universidade Federal de

Juiz de Fora.

E-mail: f.rodriguesbarbosa@gmail.com

\begin{abstract}
Resumo
O presente artigo é fruto de nossas pesquisas em política comparada entre jovens democracias latino-americanas e centro-europeias pós 1989 . Neste espaço, abordamos alguns dos autores mais influentes no debate sobre o populismo na Europa Central. Como estudo de campo e de caso, analisamos o último e mais bem-sucedido novato partido político da República Tcheca, o ANO2011 (SIM2011), classificado como um fenômeno do populismo no país, buscando, assim, encontrar as características atribuídas ao populismo em seu estatuto, programa político e discursos públicos. Passamos, então, ao confronto entre as abordagens que caracterizam o populismo na Europa Central, juntamente com os dados fornecidos pela nossa pesquisa. Como resultado, rejeitamos, até o presente momento a ocorrência do populismo na região central da Europa, argumentando que o que está em curso se trata de uma reação de novos grupos de centro-direita descontentes com as elites herdeiras de 1989.
\end{abstract}

\section{Palavras-chave}

Populismos. Partidos Políticos. Democracia.

\begin{abstract}
This paper is the result of our research on comparative politics among young Latin American and Central European democracies after 1989. In this space, we approach some of the most influential authors in the debate on populism in Central Europe. As a study case, we analyze the last and most successful new political party of the Czech Republic, the ANO2011 (YES2011), classified as a phenomenon of populism in the country, thus seeking to find the characteristics attributed to populism in its statute, political program and public speeches. We then turn to the confrontation between the approaches that characterize populism in Central Europe, together with the data provided by our study case. As a result, we have so far rejected the occurrence of populism in central Europe, arguing that what is underway is a reaction of new center-right groups unhappy with the 1989 heiress elites.
\end{abstract}

\section{Keywords}

Populism. Political Parties. Democracy. 


\section{Introdução: Apresentando o Sistema Político Tcheco}

De todo o território europeu, a região que compõe a Europa Central é aquela apontada como o epicentro de emergência dos recentes fenômenos políticos atribuídos a um novo capítulo da história do populismo europeu (SKOLKAY, 2000; RUPNIK, 2007; KRASTEV, 2006 e 2007; SMILNOV e KRASYEV, 2008; HANLEY e SIKK, 2014). O fator fundamental, utilizado para explicar essa conjuntura, reside na precoce relação de desilusão e apatia política dos cidadãos com os partidos políticos e as elites herdeiras das democratizações de 1989. Ambos os sentimentos emergiram da incapacidade dos partidos políticos, criados durante o período de transição e abertura política, em atender as principais demandas de seu eleitorado. Com efeito, a situação atingiria um ponto agudo quando as populações dos países centro-europeus passaram a assistir os principais partidos políticos envolvidos com aquela que é hoje considerada a forma mais predatória de prática da corrupção na Administração Pública: a captura do Estado (HELLMANN, JONES e KAUFFMANN, 2000; SALAMANCA, 2008; BARBOSA, 2017b).

Como resultado, novos e eleitoralmente bem-sucedidos partidos políticos centro-europeus vem se apropriando dos quadros institucionais de combate à corrupção. No entanto, os resultados de suas intenções e estratégias tem se mostrado, na maioria dos casos analisados (KRASTEV, 2007; SMILNOV e KRASTEV, 2008; HAVLIK e HLOUSEK, 2014; BARBOSA, 2016), apenas na direção do ganho de apoio popular para vencer eleições e/ou entrar no parlamento do que, de fato, de combater a corrupção. A estratégia de incluir em seus programas políticos demandas populares não atendidas pelos partidos herdeiros de 1989, somado a um novo tipo de retórica discursiva antiestablishment ${ }^{1}$ e o esquecimento de suas principais promessas de campanha tão logo são eleitos levou, tanto a imprensa quanto acadêmicos da Europa Central, ao diagnóstico de uma nova ascensão populista na região, tratando o fenômeno de maneira vaga e o simplificando como um regime de demagogos que falseiam a verdade (BARBOSA, 2016 e 2017a), excluindo fatores importantes, como o fato deste fenômeno emergir em momentos de transitoriedade de um regime político em crise e que encontra-se incapaz de sustentar e conservar suas políticas, sendo obrigado a negociar com elementos democratizantes em expansão ou ser derrotados pelos mesmos.

\section{O Populismo no Debate Centro-Europeu}

A definição de populismo mais influente sobre os trabalhos de acadêmicos centro-europeus tem sido sugerida por Cas Mudde $(2007,2013)$ e Mudde e Kaltwasser (2011), em seus estudos sobre os novos partidos europeus de centro e direita. $\mathrm{O}$ autor define o populismo desses partidos como uma ideologia afiliada ao centro (thin-centred), que trata a sociedade separada em dois grupos homogêneos e antagônicos, composto de um lado pelas "pessoas puras", defensoras da vontade geral do povo, versus o outro lado, composto por uma "elite corrupta". Destaca-se que as ideologias centristas, nesse contexto, estão caracterizadas por um vazio de respostas às principais questões políticas e sociais. No entanto, o aludido vazio, ou indefinição ideológica, trata de tornar o discurso do partido político compatível com outros sistemas de crenças dentro da bifurcação esquerda/direita, alinhando-se de acordo com o ânimo da população. Como nas palavras de Mudde e Kaltwasser (2011: p. 2): "[a]s características ideológicas atribuídas ao populismo dependerão do contexto sócio-político em que o populista busca mobilizar os atores".

Embora não sendo um estudo específico sobre populismo, "[o] Estilo Paranoico na Política Americana", de Richard Hofstadter (1964), é frequentemente citado nos trabalhos que se encarregam da abordagem do populismo na Europa Central. Hofstadter define o estilo paranoico como "um modo de expressão (ou retórica) caracterizado pelo exagero e desconfiança em um ambiente conspiratório e apocalíptico" (HOFSRADTER, 1964: p. 1), que constrói uma trama discursiva onde o que está em jogo e precisa ser identificado pelos cidadãos é uma iminente ameaça que visa tomar o controle da sociedade e mudar seus valores tradicionais mais fundamentais (a América, para Hofstadter). Não fugindo às demais construções políticas discursivas, faz-se necessário a identificação de quem são os "inimigos" (da América) para então ser possível uma configuração e estratégia de mobilização e combate.

A influência desses autores pode ser vista, por exemplo, nas obras de Andrej Skolkay (2000), um dos mais respeitados estudiosos do populismo na região central da Europa, o qual define o fenômeno da seguinte forma:

O populismo é uma forma de retórica política fortemente antagônica, que simplifica extremos e oferece, na maioria das vezes, soluções vagas. O político 
populista apresenta-se como um homem comum que entende as pessoas, em contraste com as elites corruptas, incapazes e/ou impróprias para governar. Ele diz representar todos os não-privilegiados ou desfavorecidos, sub-representados, ou qualquer outro grupo relativamente grande e vagamente definido (SKOLKAY, 2000: p. 2).

Skolkay (2000), visando responder algumas questões que teriam levado à emergência do populismo nas ex-repúblicas soviéticas, aborda uma gama de obras de caráter psicossocial que se encarregaram de traçar uma identidade das novas sociedades pós-comunistas². Reproduzimos aqui os principais traços psicológicos ressaltados pelo autor:

um indivíduo não disposto a assumir riscos, hostil para com fair play e valores pluralistas; pessimismo, paternalismo e passividade, fracos valores morais, herdeiro da mentalidade totalitária como uma visão de mundo exclusivamente em termos da distinção amigo/inimigo, propenso à intolerância e a hipocrisia, com regras autoritárias de comportamento; falta de paciência com assuntos políticos e tendência natural para procurar soluções fáceis e radicais; ausência de sintonia entre as novas elites e as necessidades dos cidadãos (SKOLKAY, 2000: p. 5).

Tal conjuntura psicológica, levantada por Skolkay (2000), somada à aquilo que Krastev (2006: p. 1) aponta como a "fórmula mágica" do 'populismo"' centro-europeu, nos coloca de frente com uma combinação explosiva que vem promovendo o sucesso discursivo e eleitoral de tais partidos na região:

raiva autêntica, ódio desenfreado das elites, indefinição sobre a política, igualitarismo econômico, conservadorismo cultural, radicalismo compassivo, euroceticismo medido e anti-capitalismo, nacionalismo declarado, xenofobia não declarada, retórica anticorrupção (KRASTEV, 2006).

As novas lideranças e partidos políticos mesclaram uma forte retórica anticorrupção com elementos antiestablishment, produzindo na região o que ficou conhecido como o "discurso da falência liberal" (KRASTEV, 2006 e 2007; SMILNOV e KRASTEV, 2008). Nesse discurso, os ataques se dirigem ao que teria sido uma falta de visão, por parte dos partidos tradicionais, de como o problema da corrupção figurava nos sentimentos populares e a incapacidade das lideranças do establishment de lidar com o problema:

Os liberais perceberam a corrupção como um problema institucional que requer uma resposta com foco em maior transparência e reformas institucionais. Mas, aos olhos do público, a corrupção era um problema moral ("Deus não aceita subornos"), exigindo políticos honestos no poder. Em segundo lugar, os liberais consideraram o discurso de combate à corrupção como sendo uma questão de justiça, enquanto que para o público foi um discurso sobre a crescente desigualdade social. Em terceiro lugar, os liberais acreditaram que a corrupção foi causada pelo Estado ser demasiado poderoso e grande, e defendeu a privatização rápida e um Estado mínimo, enquanto a maioria das pessoas apontava a culpa no poder do mercado e pediam uma revisão dos acordos de privatização mais escandalosos. Em quarto lugar, os liberais viram o discurso de combate à corrupção como uma oportunidade para legitimar o capitalismo. Mas a maioria de espíritos viu isso como uma oportunidade para deslegitimá-lo sem correr o risco de ser acusado de comunismo ou outras doenças infecciosas (KRASTEV, 2006: 7).

De acordo com Skolkay (2000); Krastev (2006 e 2007); Rupnik (2007), Smilnov e Krastev (2011), os liberais se condenaram ao despolitizar o combate à corrupção, transformando-o num simples instrumento para suas reformas institucionais. O discurso político liberal, centrado na corrupção, teria simplificado as escolhas políticas dos eleitores, reduzindo o processo através de uma escolha de cunho moral "entre o governo corrupto e a oposição ainda não corrupta. Enquanto isso, 0 grito de guerra da cruzada anticorrupção é: "se livrar de todos eles!"'" (KRASTEV, 2006: p. 9). Dessa forma, o discurso de "falência liberal" buscou atacar tal projeto como "fadado ao fracasso por ser 
Flávio Rodriguês Barbosa

moralmente e politicamente falho" (RUPNIK, 2007: p. 20). No geral, os discursos dessas novas lideranças políticas apontam como resultado das mazelas atuais a total falência das elites em termos morais e políticos em conjunto com a corrupção econômica. $\mathrm{O}$ foco de suas campanhas eleitorais vem se dirigindo contra as elites da era da transição em retóricas que empregaram desde a total descomunização do Estado até o combate à corrupção.

Tanto para Skolkay (2000), quanto para Krastev $(2006,2007)$, a força motriz da política populista na Europa Central reside na fraqueza das instituições democráticas. 0 populismo na região é visto como um fenômeno que emerge sempre atrelado aos tempos de profundas crises de hegemonia, onde sua capacidade para galvanizar novas formas de engajamento político se eleva especialmente na forma de movimentos sociais de massa e organizações partidárias. As razões para o sucesso dessa mobilização são apontadas para um momento de grande insatisfação e desilusão, onde as pessoas tendem a ser impacientes, ansiosas e intolerantes, ficando sensíveis às soluções extremas e que pregam soluções aparentemente rápidas e fáceis para a retomada da "normalidade". Nesse sentido, pode-se concluir juntamente com os autores que as políticas populistas têm surgido na região como uma estratégia para que os políticos sinalizem aos eleitores que suas políticas futuras estarão de acordo com os interesses gerais da população.

Contrários à corrente influenciada por Mudde (2013), e seguindo uma linha mais próxima a de Ernesto Laclau (2005a), figuram autores como Canovan (2002), Jansen (2011) e Urbinati (2014). Esse conjunto de autores enxergam o populismo como um fenômeno de capacitação para gerar consequências positivas para uma governabilidade democrática, sendo o populismo, nas palavras desses autores, uma "sombra da democracia liberal". O argumento principal dessa corrente reside no fato de que, ao se apoiar em políticas de inclusão que ampliam a participação democrática de grupos anteriormente marginalizados, a nova onda do populismo exerce pressão nos movimentos e partidos políticos concorrentes para que façam o mesmo ${ }^{3}$. A questão comum levantada por essa corrente visa saber se o populismo recente deve continuar sendo visto como uma ameaça ou um fenômeno corretivo para a democracia liberal.

Nadia Urbinati (2014), por exemplo, afirma que o populismo é uma estratégia que reequilibra a distribuição do poder político entre os grupos sociais tradicionais e os emergentes. A tensão entre "nós" versus "eles" - trabalhada pela autora através da tensão populismo versus democracia liberal - decorre da maneira em que estas duas forças políticas percebem a relação entre o povo (sustentado no argumento da vontade geral) e as instituições representativas. A autora ressalta que, para os populistas, a principal tarefa das instituições políticas não é servir como sistemas de checks and balances ou como protetores dos direitos civis, mas como ferramentas instrumentais para traduzir a vontade da maioria em decisões políticas ${ }^{4}$.

Margaret Canovan, (2002) entende o populismo como um movimento mobilizado em torno de uma ideologia, apresentando em seu discurso "uma reivindicação de legitimidade que repousa sobre a ideologia democrática da soberania popular e no governo da maioria", isto é, um retorno a uma "verdadeira" democracia, liderada pelo "povo" e não pelas elites políticas profissionais" (Canovan, 2002: p. 25 Apud. Gidron e Bonikowski, 2013: p. 19). Jansen (2011) argumenta que, em vez de considerar o populismo como uma ideologia, devemos abordá-lo como um projeto político e sua definição estabelecida através de suas práticas discursivas e estratégias de mobilização. Assim, o autor define como mobilização populista:

Qualquer projeto sustentado, em grande escala política, que mobiliza normalmente os setores sociais marginalizados em ação política publicamente visível e controversa, ao mesmo tempo em que se articula uma retórica nacionalista anti-elite que valoriza as pessoas comuns (Jansen, 2011: p. 82).

Para Jansen, o discurso populista "postula a unidade social natural e inerentemente virtuosa de um "povo" (JANSEN, 2011: p. 84). As pessoas comuns vão então figurar em uma relação antagônica com uma "elite antipopular". 


\section{Características dos Novos Partidos Políticos Centro-Europeus Relacionados com um Populismo}

Em termos de modelos de organização, os novos partidos se assemelham aos modelos catch-all: são frouxamente organizados, compostos em sua maioria de técnicos experientes, possuindo baixa institucionalização e dão pouca importância à filiação partidária. A novidade genuína, ressaltada por Hanley e Sikk (2014), figura no fato de que são unidades políticas não sucessoras de nenhum partido parlamentar anterior, têm novos nomes e (geralmente) são organizados sem nenhuma figura importante da política democrática do passado entre seus principais membros.

Nossas análises sobre novos partidos políticos centro-europeus, classificados como populistas, nos possibilitou extrair as seguintes características gerais: 1) Discurso da promoção de uma Nova Política: através de exigências quanto a mudança na forma como a política é conduzida, sendo oferecido em seu lugar uma política "antipolítica"; 2) Personalidade: exercida na forma como lideranças se apresentam aos eleitores, se denominando cidadãos descontentes ou políticos "antipolíticos", sem passado ou experiência com a política; 3) Posição centrista e recusa ideológica: projeção das clivagens tradicionais de esquerda/direita como culpadas por toda ineficiência administrativa e direcionamento para a chamada ideologia centrista e cidadanista, também sustentada por uma apologia do senso comum; 4) Foco discursivo no combate à corrupção e ao establishment, prometendo combater as práticas de corrupção e renovar a política, projeto que só será bem-sucedido com a reprovação dos partidos tradicionais e a retirada de seus políticos do parlamento; 5) Democracia direta: presente nas promessas de capacitação dos cidadãos para o exercício da democracia direta e participação popular na coautoria das políticas públicas do partido (podendo tal realização ser prometida através de seu website na internet); 6) Novos nomes: mais diretos e simplificados, que reforçam tanto a recusa das clivagens tradicionais como a política dos partidos tradicionais com estilo de um comando ou palavras de ordem (Barbosa, 2016). Dessa forma, encontramos um campo político dividido nas seguintes condições:

Quadro 1. Bipolarização do Campo Político

\begin{tabular}{|l|l|}
\hline Establishment & Antiestablishment \\
\hline Inimigos & Amigos, Nós \\
Mentira, Traição, Usurpação, Eles Corrupção, & Cidadãos Iguais, Senso Comum \\
Estagnação, Arcaísmo & Não-políticos \\
Auto interesse, Ideologias, Incompetência & Pureza \\
Direita/Esquerda & Nova Política \\
Área de Perigo & Povo acima das Ideologias, Eficiência \\
Contaminação e Contágio & Democracia Direta \\
Gorduroso, Nocivo & Light, Saudável \\
\hline
\end{tabular}

Fonte: Barbosa (2016)

A escolha dos nomes também apresenta uma clara rejeição dos modelos clássicos de oposição entre direita e esquerda (liberais, socialistas, comunistas ou alguma versão nacionalizada de ambos, trabalhando dentro de uma dimensão de leveza ${ }^{5}$ que lembra produtos para consumo no mercado, o que nos leva à característica 7) a criação do partido como uma marca (brand). São exemplos que encontramos nos principais partidos novos da região, como no eslovaco: Smer (Direção), no húngaro Fidesz - Magyar Polgári Szövetség ${ }^{6}$ (Fidesz é a abreviação de Fiatal Demokraták Szövetsége: Aliança Jovem Democrata). Na Bulgária, do Natsionalno dvizhenie za stabilnost $i$ vazhod (Movimento Nacional pelo Progresso e Estabilidade). No polonês: Prawo $i$ Sprawiedliwość - PiS (Lei e Justiça). Nos partidos tchecos: ANO 2011 (SIM 2011), TOP 09 (Tradice Odpovednost Prosperita - Tradição, Responsabilidade e Prosperidade), WV - Veci Verejné (Assuntos Públicos) e Úsvit prímé demokracie (Alvorecer da Democracia Direta).

A maior parte do sucesso eleitoral desses novos partidos se fez através da astúcia com que seus membros construíram suas retóricas de ataques a seus rivais. Eles perceberam a desilusão e 0 distanciamento entre partidos e eleitores, devido ao modelo de governança por estes adotados, ouviram as principais demandas da população e incluíram algumas em suas plataformas de governo. 
Flávio Rodriguês Barbosa

Mas o principal seria a adesão, em suas estratégias políticas, a construir imagem de si em semelhança com o povo, e antagoniza-la àquela com que seus adversários políticos se mostravam perante os olhos da população. Contra a figura do corrupto e dos partidos corrompidos, edificou-se uma "nova elite pura" (por não ter passado e experiência na política) e composta por cidadãos igualmente descontentes, dignitários do poder político e redentores da população (BARBOSA, 2016).

Alguns exemplos de novos partidos bem-sucedidos atrelados ao populismo ${ }^{7}$ podem ser encontrados em casos como o da Bulgária, em 2001, onde ex-rei do país, Simeon Saxe-CoburgGotha, funda em abril do mesmo ano o partido político Natsionalno dvizhenie Simeon II (Movimento Nacional Simeon II), o qual passou a se chamar em 2007 por Natsionalno dvizhenie za stabilnost $i$ vazhod (Movimento Nacional pelo Progresso e Estabilidade) e com apenas três meses de campanha causou um terremoto eleitoral por ganhar a maioria no parlamento búlgaro. A vitória significativa do ex-rei "levou os analistas, daquela época, a enxergarem precocemente tal feito como o triunfo final do populismo" (Krastev, 2006: p. 2). Sobre o discurso do ex-rei, Krastev (2006) ressalta um caráter vago e perigosamente oportunista. As abordagens e estratégias políticas de Simeon II nos veículos de mídia eram moralistas e não programáticas. No entanto, logo nos primeiros anos de governo, o partido de Simeon fizera sua adesão à Internacional Liberal, o que teria sido um fator crucial para "trazer a Bulgária para as negociações de inclusão na União Europeia" (KRASTEV, 2006: p. 3). 0 mesmo truque foi repetido pelo ex-prefeito de Sofia, Boyko Borisov (ex-guarda-costas de Simeon), o qual ganhou a eleição como um "radical populista" e, um dia depois, começou a governar como um liberal comum.

Em 2007, na Eslováquia e na Polônia, lideranças de partidos classificados como populistas fizeram coligações com partidos nacionalistas de extrema-direita, construindo um tipo de presença no governo que teria sido impensável antes da adesão à UE (SMILNOV e KRASTEV, 2008). Na Polônia, por exemplo, um discurso que mesclou uma transição caracterizada pelo "pecado original" com a ideia de uma "revolução traída", foi construído originalmente na retórica de sucesso dos gêmeos poloneses Jaroslaw Kaczynski e Lech Kaczynski ${ }^{8}$, ambos do PiS. Os irmãos Kaczynski apresentaram em seus discursos uma trajetória da nova democracia polonesa que teria sido sequestrada pelas elites pós-comunistas, num ambiente conspiratório onde as instituições fundamentais da democracia parlamentar e da economia de mercado foram secretamente vendidas pelos ex-comunistas e seus antigos oposicionistas. Afirmaram que a transição, negociada em 1989 entre ex-dissidentes e ex-comunistas, permitiu a imposição, pelos primeiros, de sua agenda liberal de "democracia procedural", ao mesmo tempo em que os últimos se convertiam ao capitalismo e a livre iniciativa (KRASTEV, 2006).

A instrumentalização da questão política, levada a cabo pelos gêmeos Kaczynski, se fez acompanhada de um self service de argumentos autoritários: para "limpar a casa, expurgando a corrupção e os agentes comunistas, por isso precisamos de mais poderes em nossas mãos e, portanto, devemos acabar com algumas restrições constitucionais e institucionais" (RUPNIK, 2007: p. 22). Em nome de uma luta contra uma suposta rede de governos politicamente perigosos e corruptos durante os anos de transição, a Polônia dos irmãos Kaczynski recorreu a métodos autoritários, captura do Estado e retóricas homofóbicas e nacionalistas ${ }^{9}$.

\section{Análise de Caso: A República Tcheca e o partido político ANO 2011 4.1 Sistema Político}

Criada em $1^{\circ}$ de janeiro de 1993, os líderes políticos tchecos, principalmente no período de transição do regime e dissolução da Tchecoslováquia, costumam exaltar a experiência liberal existente no país durante o período entre as duas Grandes Guerras. A atual Constituição entrou em efeito no mesmo dia em que emergia a nova república, definida como um Estado Unitário, descentralizado, de sistema parlamentarista e governo representativo e pluripartidário.

O Primeiro-Ministro é o Chefe de Governo e mantém poderes consideráveis, incluindo o direito de determinar a maior parte da política interna e externa, mobilizar a maioria parlamentar e nomear ministros. O Presidente da República é o Chefe de Estado e representa o Poder Executivo do país em conjunto com o Poder Legislativo tcheco. O Chefe de Estado formal tem poderes específicos como: o direito de veto, nomear juízes do Tribunal Constitucional, indicar o primeiro-ministro e, sob raras e especiais condições, dissolver o parlamento. 
O Parlamento da República Tcheca é bicameral, composto pela Câmara dos Deputados (Poslanecká Smevnova) e o Senado (Senát). A Câmara dos Deputados é composta por 200 cadeiras, enquanto o Senado é configurado com 81 assentos. Os deputados são eleitos a cada quatro anos em eleições diretas e proporcionais de lista aberta, onde cada eleitor vota através da lista do partido de sua escolha, podendo selecionar quatro votos para cada um de seus candidatos preferenciais. Exigese que um partido deve obter pelo menos $5 \%$ da votação nacional para obter representação parlamentar ( $10 \%$ no caso de uma coligação dos dois partidos, $15 \%$ para uma coalizão de três partidos, $20 \%$ para uma coalizão de quatro ou mais partes), com os assentos distribuídos entre os partidos e coligações de acordo com o sistema de D'Hondt. Um candidato que receber mais de $5 \%$ dos votos preferenciais no nível regional será colocado no topo da lista de partidos. Nos casos em que vários candidatos receberem mais de 5 por cento dos votos preferenciais, eles serão colocados na lista em ordem decrescente com base no número total de votos preferenciais que receberem. Vagas criadas entre as eleições gerais são preenchidas por suplentes eleitos. $O$ voto não é obrigatório.

Já os membros do Senado têm mandato de seis anos, sendo um terço dos senadores renovados a cada dois anos. Há 14 distritos eleitorais que coincidem com as regiões administrativas do país. Cada distrito tem aproximadamente o mesmo tamanho e a eleição acontece em dois turnos. Tanto a Câmara dos Deputados quanto o Senado são eleitos através do sufrágio universal e voto secreto dos eleitores com mais de dezoito anos de idade. Enquanto as eleições para a Câmara dos Deputados seguem o sistema proporcional, as eleições para o Senado são realizadas através do sistema majoritário. Para concorrer à Câmara dos Deputados é necessário que o cidadão tenha o mínimo de vinte e quatro anos, enquanto que para concorrer ao Senado é necessário ter completado o mínimo de quarenta anos.

A instância judicial máxima do país é a Suprema Corte. A Corte Constitucional é um corpo judicial encarregado e sob proteção do governo constitucional, composto por quinze juízes para o exercício de suas funções fixadas em dez anos. Os juízes são indicados e nomeados pelo presidente da república e obtém confirmação do Senado, não podendo ser renomeados ou transferidos para outras cortes contra seu desejo. Qualquer cidadão tcheco habilitado para concorrer às eleições, desde que graduado em Direito e em trabalho ativo na profissão nos últimos dez anos pode ser indicado para juiz da Corte Constitucional.

Um partido político, para entrar oficialmente em atividade que o conduza a concorrer por lugares nas eleições, necessita de registro junto ao Ministério do Interior através da apresentação de uma petição assinada por pelo menos 1000 cidadãos tchecos, estando suas atividades sob regulação da lei 422/1991 ${ }^{10}$. Qualquer partido político pode ser dissolvido se atuar contra o sistema constitucional democrático e as leis do país. Outro fator de dissolução do partido político se encontra na submissão de um falso relatório de finanças. Aos partidos políticos estão vetadas qualquer condução de atividade empresarial ou finalidades lucrativas, sendo a mais importante fonte de renda destes o repasse feito através do orçamento estatal, onde a distribuição de dinheiro é feita de acordo com uma escala relacionada aos votos e números de assentos obtidos ${ }^{11}$, e contribuições privadas. A partir de 1997, com o "escândalo das campanhas de financiamento", realizou-se uma série de mudanças de forma a restringir a contribuição de particulares aos partidos e também na forma de aceitação destes para com as doações.

A República Tcheca não definiu quotas de gênero para candidatos. O número de mulheres na Câmara dos Deputados tem sido em torno de 30 assentos. As eleições realizadas em 2006 marcaram a entrada das mulheres na Câmara e no Senado ${ }^{12}$, com 31 mulheres conquistando assentos na câmara (15,5\% dos deputados) e dez mulheres obtendo assentos no Senado (12,3\% dos senadores).

\subsection{O Partido Político ANO 2011}

A partir de 2010, chega a vez de a República Tcheca viver seu terremoto eleitoral. Partidos tradicionais, como os democratas cívicos (ODS), democratas cristãos (KDU-CSL) e os sociais democratas tchecos (CSSD), que herdaram as tarefas democratizantes das revoluções de 1989 e protagonizavam a cena até então, começam a perder espaço para os partidos novatos. Apesar da vitória dos democratas cívicos (ODS) nas eleições de 2010, o pleito amargou o segundo pior índice de participação eleitoral da história do país, em muito atribuído pelos escândalos de corrupção e 
captura do estado envolvendo os principais grupos empresariais e partidos políticos tchecos ${ }^{13}$. Como resultado, dois novos partidos caracterizados como populistas, o TOP 09 e o Véci Verejné (Assuntos Públicos), conquistaram importantes cadeiras logo em sua primeira eleição disputada ${ }^{14}$, integrando, posteriormente, a coalizão governista. Por outro lado, as eleições de 2010 também ficaram marcadas pela ausência dos democratas cristãos (KDU-CSL) no parlamento, terceiro maior partido do país ${ }^{15}$.

Três anos depois, com as eleições antecipadas de 2013, devido a mais escândalos de corrupção envolvendo mais uma vez os democratas cívicos (ODS), chega a vez de mais dois partidos novatos e recém-fundados entrarem no parlamento: o ANO 2011 (SIM 2011 - fundado em 2011) e o ÚSVIT (ALVORECER - fundado em 2013, poucos meses antes do início da corrida eleitoral ${ }^{16}$ ). Apesar da vitória dos sociais democratas (CSSD), o ANO 2011, utilizando as mesmas estratégias dos novos e bem-sucedidos partidos da eleição anterior, conquista o segundo maior número de cadeiras no parlamento ${ }^{17}$, se tornando uma peça-chave para a coalizão governista. Em ambos os casos, os partidos novatos fizeram sucesso com campanhas antietablishment para, no fim, integrarem o governo juntamente com partidos alvos de suas retóricas (BARBOSA, 2016). O pleito de 2013 também marcou o maior fracasso eleitoral dos democratas cívicos (ODS), conquistando apenas 16 de 200 cadeiras no parlamento $(7,73 \% \text { de votos })^{18}$.

O partido político ANO 2011 foi fundado no ano de 2011 pelo empresário Andrej Babis, bilionário do setor petroquímico, como um movimento cívico de cidadãos insatisfeitos com a condução das políticas econômicas e o quadro de corrupção existente no país ${ }^{19}$. A palavra ANO é um acrônimo de Akce Nespokojených Obcanu (Ação dos Cidadãos Insatisfeitos), e em tcheco ano quer dizer sim. O partido, que também é visto como um projeto pessoal de Babis, se notabilizou por sua postura discursiva antiestablishment, antipolítica tradicional e anticorrupção. Sua rápida entrada e ascensão na política, seus discursos que, ora se faziam próximos da esquerda e ora próximos de um liberalismo conservador, assim como a estrutura em que o ANO 2011 foi edificado e centralizado na figura do empresário, fez a imprensa europeia comparar Babis e seu partido com outra conhecida figura política e empresarial do velho continente: Silvio Berlusconi. A partir daí, o empresário passou a ser muitas vezes referido (ironicamente) como "Babisconi"20.

No estatuto do ANO 2011 o senso comum é destacado como elemento-chave para promoção de políticas correspondentes às necessidades dos cidadãos. Seu discurso centrista resume os problemas nacionais a uma simples reformulação do modo de gestão do país, com destaque pelo distanciamento de visões ideológicas ${ }^{21}$. O partido diz perceber a política como um serviço público e, assim: "colocar mais ênfase em achar soluções é mais importante do que rótulos ideológicos"22.

O ANO 2011 entende que tal rotulação cria "situações onde diferentes tópicos se tornam coisas desnecessariamente politizadas às custas de um construtivo debate sobre achar soluções ótimas"23. Assim, no estatuto do partido o senso comum ganha status de abordagem humanística em oposição ao tratamento ideológico (localizado no establishment), definidos no documento como burocratizantes por politizar desnecessariamente os problemas políticos: "Nós estamos certos de que o senso comum e as abordagens humanas são sempre um melhor caminho ao invés de rigidez burocrática"24.

Nos primeiros parágrafos de seu programa eleitoral para as eleições de $2013^{25}$ o partido de Andrej Babis apresenta a si como "um movimento que visa mudar a cultura política do país" (ANO 2011 Volební Program 2013, p. 1). Tal como em seu estatuto, reforçou uma posição não ideológica, atribuindo a esta os problemas de ineficiência política que "impedem uma gestão dos mais capacitados" (ANO 2011, Volební Program 2013: p. 1). Logo a seguir, uma ênfase é posta sobre sua composição orgânica, onde seus membros e candidatos são apresentados como o resultado de um 
processo de seleção de cidadãos com bem-sucedidas histórias de vida (ANO 2011, Volební Program, 2013: p. 1). Algo muito raro envolvendo o ANO 2011 é encontrado no folder da plataforma da campanha eleitoral direcionada à cidade de Brno, na região da Morávia, se tratando da única vez que encontramos um documento com uma auto-referência do movimento como partido político:

Somos parte de um partido político com uma história curta, mas com um grande trabalho que gostaríamos de contribuir para o desenvolvimento da comunidade e melhorar a vida de todos os cidadãos. Para colocar tudo isso em conjunto, nós montamos uma equipe de profissionais e patriotas com diferentes profissões, educação e experiência, que não apenas prometem, mas estão comprometidos. Trabalho honesto, feito com a sua ajuda para uma mudança melhor (Portal ANO 2011. www.anobudelip.cz).

O ANO 2011 possui um processo de filiação que causou muita controvérsia. O processo de adesão ao partido impõe várias dificuldades para a entrada de membros: o cidadão interessado precisa anexar ao pedido de filiação uma cópia de seu Curriculum vitae para ser avaliado, podendo também ser convocado para uma entrevista pessoal para então ser aceito ou rejeitado. Por outro lado, não passam por tal processo burocrático as figuras convidadas diretamente pelo presidente do partido. No entanto, recrutar membros que sejam de interesse direto do fundador também serve para construir a imagem da competência profissional que atuará nos quadros públicos que o partido quer passar aos eleitores. Daí apresentar seus membros como um corpo especializado de patriotas dotados de histórias de vidas bem-sucedidas.

O caráter seletivo do método de recrutamento do ANO2011, embora não conste em nenhum documento oficial do partido, reside na própria vontade de seu fundador de que o partido tenha um baixo número de membros, garantindo o controle da organização para si com níveis baixos de institucionalização. Isso ficou evidente na entrevista concedida por Vera Jarouvá, vice-presidente do movimento, ao jornal MF Dnes (06/05/2013), ressaltando o desejo do movimento em contar apenas com pouco mais de mil integrantes. Ao dificultar e, na verdade, rejeitar a grande adesão em seus quadros, o partido também revela que seu interesse é contar apenas com pessoal especializado que tenha utilidade para a promoção dos interesses de seu fundador. Isso implica em uma grande inversão de valores, pois o simpatizante que deseja ingressar na organização política para se dedicar à vida pública, cede sua vez a uma organização que busca profissionais desejosos de entrar na política para trabalhar como funcionários rent seekers do partido político.

Outro aspecto que o partido dá ênfase em seu programa político é na criação de um Estado funcional, gerenciado e administrado por especialistas - com o descredenciamento dos políticos do establishment. É em sua promoção que todas as demais ideias e propostas são trabalhadas. Uma delas é a defesa do país como uma respeitável marca (brand) no exterior e seu gerenciamento como uma empresa. $O$ interessante, nesse argumento, é que ele aparece envolvido por parciais reconstruções históricas de um passado glorioso em que tal estado tenha existido e necessita ser resgatado. O ponto de partida figura na emblemática república erguida em 1918:

Na Primeira República, para tornar sua marca clara e definida, ela foi sistematicamente construída com regras simples e estáveis e com o supervisionamento de seu cumprimento. Ela abriu a porta, defendeu e apoiou aqueles que queriam e poderiam dar uma mão" (ANO 2011. Volební Program 2013).

A isso, soma-se uma engenhosa utilização da sigla do partido como um formidável utensílio propagandístico:

Sim para uma Boa Marca: Nosso país foi durante muitas décadas uma boa marca para o mundo inteiro. Ele tem estado na vanguarda da engenharia mundial, na indústria têxtil, de calçados, de vidros e de alimentos. Nomes de empresários como Bata, Skoda, Kolben ou Clement foram apreciados e tiveram o respeito universal. Atrás de seu sucesso, milhares de pessoas tiveram a oportunidade de aplicar suas habilidades. Pessoas que sabiam que toda a liberdade e justiça andam de mãos dadas com a responsabilidade e que a democracia é um trabalho em equipe que exige um elevado grau de solidariedade (ANO 2011. Volební Program: s/n, 2013). 
A campanha eleitoral do ANO 2011 começou com uma série de apresentações do partido em outdoors e tinha como tarefa introduzir novos assuntos políticos e promover novos rostos aos eleitores. Do início ao fim, a imagem do ANO 2011 esteve vinculada a de Andrej Babis. O partido, graças aos recursos de seu fundador, contratou duas grandes agências de marketing político para trabalhar em uma massiva campanha: a norte-americana PSB ${ }^{26}$ e a agência tcheca Campaigns.cz. 0 trabalho das agências envolveu um amplo trabalho de alinhar o novo partido político com os sentimentos expressos da população, levando o ANO 2011 a ser o partido que mais recorreu a investimentos em pesquisas de opinião pública e serviços de marketing e consultoria, gastando um total neste segmento de $20.275 .194,42$ milhões de coroas ${ }^{27}$. As primeiras mensagens tiveram como direção a promessa do fim do clientelismo e nepotismo no país e o início de uma nova cultura política, acompanhado de slogans que aproveitavam o trocadilho fornecido pelo acrônimo do partido: Ano. Miluji te ("Sim. Eu te amo!), Ano. Chceme te! ("Sim. Queremos você!"). Até finalmente o partido adotar seu slogan final: "Ano. Bude lip! ("Sim. Será Melhor!") (LUZAR, 2014: p. 21).

O ANO 2011 também adotou uma postura discursiva antiestablishment com suas retóricas construídas para responsabilizar as elites do país e os partidos tradicionais, notoriamente o ODS e 0 CSSD, pela gestão incompetente dos negócios públicos, pela corrupção e por qualquer outra crise existente e identificada no país. Um slogan que figurou em muitos outdoors, durante a campanha eleitoral, ilustra bem a retórica do ANO 2011: "Nejsme politici. Pracujeme!28" (Não somos políticos. Nós trabalhamos!").

A ideia do partido era passar aos eleitores a mensagem de que políticos não se interessam pelos assuntos pertinentes aos cidadãos, são incompetentes, corruptos, não trabalham, estão desacreditados e precisam ser removidos: "[0] ODS e o CSSD estão paralisados e são incapazes de fazer uma reforma29"; "[o]s ODS não têm nada para oferecer a seus eleitores ${ }^{30 " ; ~ " ~[0] s ~ e v e n t o s ~ d o s ~}$ últimos dias, mostram o nível de desespero de nossas elites31"; "[a] atual contracampanha é uma evidência particular do desespero dos ODS, que vão às eleições sem candidato e programas fortes ${ }^{32 " ;} ;$ "[n]osso país tem um milhão de pessoas na linha da pobreza. Nosso país está esgotado. Foi saqueado, roubado. Esse é o resultado dos governos ODS e CSSD e outros políticos ${ }^{33 " .}$

De acordo com o ANO 2011, os políticos do establishment construíram um mundo que funciona na base de intrigas, brigas e crimes, reduzindo "o significado da palavra política para a tecnologia de poder dentro do parlamento, através dos partidos políticos, sem ligação com o mundo exterior ${ }^{34 "}$. Dando prosseguimento ao clima antipolítico, o partido afirma que políticos não decidem melhor do que as próprias pessoas sobre suas necessidades, mas decidem sempre de acordo com suas cobiças e interesses próprios ou de acordo com os interesses ou chantagens de grupos que os transformaram em candidatos (ANO 2011. Volební Program 2013). Dessa forma, a proposta de políticas para cidadãos finda com o programa consolidando o establishment como o inimigo da nação e o ANO 2011 como uma vanguarda de políticos:

Foram os políticos que dividiram o país para eleger aqueles que podem fazer as políticas e aqueles outros que devem manter o ritmo. Assim, uma vez a cada quatro anos se vai às urnas para escolher "um mal menor". O movimento ANO (SIM) exige uma qualidade diferente de políticos. Ele oferece pessoas que conquistaram e construíram alguma coisa. São pessoas que sabem como é difícil lutar na vida e o quanto difícil é o caminho para o sucesso. São pessoas que se esforçaram para ter sucesso e podem haver outros ${ }^{35}$.

À este discurso juntam-se outras declarações emitidas por Babis durante sua campanha eleitoral: "[g]overnar o Estado em benefício dos cidadãos, não dos políticos ${ }^{36 " ;}$ " "[o]s políticos não decidem para que todos tenham o melhor, decidem de acordo com sua própria cobiça e poder, 
tomando decisões de acordo com os interesses de lobbies e de quem os financiam como candidatos $37 " ;^{37}$ "[o] Estado pertence às pessoas e não aos políticos que o privatizaram"38" e; "[a] garantia da velha política expirou ${ }^{39 "}$.

O elemento de pureza aparece quando a campanha do partido defende a bem-sucedida trajetória pessoal de Andrej Babis. É nesse momento que a imagem do empresário se funde com a do cidadão descontente e se diferencia de um contaminado establishment: "[e]u não sou político, eu não vou roubar. Eu sou incorruptível, tenho muito dinheiro e não preciso de mais $40 " ;$; "[p]or que entrei na política? Eu fui forçado. Eu não podia ficar parado. Eu simplesmente não posso suportar o modo como este país é controlado e por quem é controlado41"; "[o] que está vencendo é o meu programa e o que é terrivelmente simples: Eu não minto. Eu não roubo. Eu trabalho42"; "[e]u não vou mentir e roubar. Eu vou trabalhar para vocês ${ }^{43}$. Q Quando em uma entrevista foi comparado à Silvio Berlusconi, Babis respondeu: "[e]le teve escândalos sexuais, sonegou impostos e enganou o Estado. Eu não farei essas coisas44".

Em outro momento, Babis se viu pressionado a responder sobre uma suposta colaboração com o StB e o regime comunista. Nesse ponto, Babis assume pela primeira vez um posicionamento no espectro ideológico, respondendo à questão da mesma maneira como os candidatos do $\mathrm{Veci}$ Verejné (Assuntos Públicos) lidaram com a mesma nas eleições de 2010 (BARBOSA, 2016): "Eu sou de direita. Eu pertenço a um outro mundo. Sou uma "direita com sensibilidade social 45 ". Pertencer a esse outro mundo, onde se é de direita com sensibilidade social, é um discurso de apresentação de uma novidade para o povo. Trata-se de uma nova cara para a direita que Babis quer representar com seu partido. A estratégia é simples e segmentada para conquistar, em sua maior parte, os eleitores de direita descontes com o ODS, ao mesmo tempo que o partido não quer se dar ao luxo de abrir mão de eleitores de esquerda descontentes com o CSSD.

O discurso antiestablishment prossegue se reforçando com a situação de crise política e desejo de mudança comparada àquela do final de 1989: "[e]stamos em um momento parecido com o anterior à Revolução de Veludo, com as pessoas cantando nas praças: nós não gostamos deles, nós não temos medo, nós não vamos mentir para vocês46". Assim, a junção de tais elementos constrói uma imagem de um redentor: "[a] República Tcheca está em uma encruzilhada. Quer que a crise continue? Verifique os partidos que causaram isso. Quer remediar? Vote SIM (ANO)"47.

A constante presença do partido e seu líder nos jornais e canais de televisão do país foi um fator fundamental para o sucesso eleitoral do ANO 2011. O problema se torna grande pelo fato de Andrej Babis também ser o proprietário de dois dos principais meios de comunicação - o MF Dnes e o Lidové -, os quais mais abordaram sua imagem, durante a campanha de maneira neutra e positiva ${ }^{48}$. O ANO 2011 conquistou $18,66 \%$ dos votos dos eleitores, obtendo 47 de 81 cadeiras no Parlamento e terminou o pleito sendo considerado o grande vencedor das eleições ${ }^{49}$. Após alguns meses de negociações o partido optou por não fazer oposição aos sociais democratas e, em janeiro de 2014, a coalizão governamental composta por CSSD, ANO 2011 e KDU-CSL foi oficialmente anunciada ${ }^{50}$.

Com o ANO 2011 fazendo parte da coalizão, Babis foi nomeado Ministro das Finanças. Nos primeiros anos na pasta, o empresário de setor petroquímico passou a receber acusações de favorecimento à Agrofert, sua principal empresa, no que concerne aos subsídios da UE ${ }^{51}$. Com uma trajetória de enriquecimento obscuro, o empresário ainda é objeto de investigação pela polícia, que trata de crimes econômicos. Constantemente, alguns meios de comunicação (como as revistas políticas de jornalismo investigativo Echo24 e Reporter) cobram de Babis uma postura transparente 
Flávio Rodriguês Barbosa

sobre seus negócios. Isso se torna um argumento pertinente quando se observa em sua biografia uma trajetória de enriquecimento intrinsecamente ligada à políticos e partidos, sobretudo o CSSD (BARBOSA, 2016). A isso soma-se o fato de que, de acordo com alguns jornais ${ }^{52}$, muitos políticos próximos de Babis já saíram de cena, o que leva a crer que a figura do empresário passou a ficar mais exposta à riscos não desejáveis.

Uma pesquisa eleitoral realizada pela agência STEM/MARK Median ${ }^{53}$, procurou identificar o perfil do eleitorado do ANO 2011, nas eleições 2013. De acordo com a agência, 1/4 de todos os eleitores entrevistados decidiram comparecer às urnas somente na última semana de campanha. Desse número, $30 \%$ declararam ter votado no ANO 2011. De todos os eleitores do partido entrevistados, 50\% responderam que escolheram votar no ANO 2011 entre o período que vai da última semana de campanha ao dia de comparecimento às urnas, e $30 \%$ disseram que escolheram o ANO 2011 por causa de suas propostas e programa político. O mesmo número de eleitores declarou ter votado no partido de Andrej Babis por acreditar que ele tem chances mais reais de mudar 0 cenário nacional comparado com os outros partidos políticos.

Os números que tivemos acesso nos mostram uma coisa similar ao caso do Veci Verejné (BARBOSA, 2017a). Assim como seu antecessor, até o dia das eleições, o ANO 2011 não conseguiu construir uma base de eleitores do partido ou estabelecer o partido como "marca", de acordo com suas intenções. Novamente o sucesso de um partido novato e relacionado a um populismo foi consequência da junção dos sentimentos de eleitores desiludidos. Os sociais democratas (CSSD) e, sobretudo os democratas cívicos (ODS), saíram do pleito enfraquecidos e o sucesso crescente dos novos partidos indica claramente que a punição por parte do eleitor tende a continuar e que não tardará para que essas novas organizações os substituam no cenário.

Nas últimas eleições, realizadas em 10 de outubro de 2017, o ANO 2011 sagrou-se como o partido político vitorioso, conquistando 78 das 200 cadeiras disponíveis no parlamento tcheco ${ }^{54}$. Pela terceira eleição consecutiva, tem-se a entrada no parlamento de algum partido novato. Mas o caso de 2017 já começa a mostrar algo diferente para nossas análises. Dessa vez, apenas um partido novato logrou sua entrada no parlamento, o SPD (Svoboda a prímá demokracie - Liberdade e Democracia Direta - fundado em 2015), conquistando 10,64\% dos votos (correspondente a 22 de 200 cadeiras). No entanto, dois pequenos partidos fundados em 2004 conquistaram apoio suficiente para entrar pela primeira vez no parlamento tcheco: o STAN (Starostové a nezávisli - Prefeitos e Independentes), o qual conquistou 5,18\% dos votos (correspondendo a 6 de 200 cadeiras) e, surpreendentemente, ocupou a terceira colocação; e o Partido Pirata Tcheco ${ }^{55}$, com 10,79\% dos votos (correspondente a 22 de 200 cadeiras) ${ }^{56}$. As últimas eleições também são interessantes por mostrarem uma recuperação eleitoral dos democratas cívicos (ODS) que, de 16 cadeiras, em 2013, pularam para $22(+9)$, enquanto os sociais democratas (CSSD) amargaram sua pior derrota, ocupando 15 de 200 cadeiras $^{57}$.

O quadro 2 mostra a configuração atual do parlamento tcheco após as eleições de 2017. Dos nove partidos que o compõem, 5 são caracterizados pelas estratégias atreladas ao populismo centro-europeu e, juntos, ocupam 135 das 200 cadeiras disponíveis (61,56\% - ANO 2011, Partido Pirata Tcheco, Liberdade e Democracia Direta, TOP 09 e Prefeitos e Independentes), deixando os partidos tradicionais, juntos, com 13 cadeiras a menos que o primeiro colocado sozinho: 65 de 200 cadeiras (32,15\% - Partido Democratas Cívico, Partido Comunista da Bohemia e da Morávia, Partido Social Democrata Tcheco e o Partido Democrata Cristão).

Quadro 2. Parlamento Tcheco em 2017

\begin{tabular}{|l|l|l|l|}
\hline Partido & Votos & $\%$ & Cadeiras \\
\hline ANO 2011 & 1.500 .113 & 29.64 & 78 \\
\hline $\begin{array}{l}\text { Partido } \\
\text { Democrata Cívico }\end{array}$ & 572.962 & 11.32 & 25 \\
\hline
\end{tabular}




\begin{tabular}{|l|l|l|l|}
\hline $\begin{array}{l}\text { Partido Pirata } \\
\text { Tcheco }\end{array}$ & 546.393 & 10.79 & 22 \\
\hline $\begin{array}{l}\text { Liberdade e } \\
\text { Democracia } \\
\text { Direta }\end{array}$ & 538.574 & 10.64 & 22 \\
\hline $\begin{array}{l}\text { Partido } \\
\text { Comunista da } \\
\text { Boêmia e da } \\
\text { Morávia }\end{array}$ & 393.100 & 7.76 & 15 \\
\hline $\begin{array}{l}\text { Partido Social } \\
\text { Democrata } \\
\text { Tcheco }\end{array}$ & 368.347 & 7.27 & 15 \\
\hline $\begin{array}{l}\text { Partido } \\
\text { Democrata } \\
\text { Cristão }\end{array}$ & 293.643 & 5,8 & 10 \\
\hline $\begin{array}{l}\text { TOP09 } \\
\text { Independentes }\end{array}$ & 262.157 & 5.18 & 7 \\
\hline
\end{tabular}

Fonte: Volby.cz

\section{Nossa Visão Sobre o Debate do Populismo na Região Centro-Europeia}

Questionamos, neste espaço, a classificação da atual conjuntura política na Europa Central como populista. O populismo, atribuído aos novos e bem-sucedidos partidos políticos da Europa Central se mostra, até o momento, como um estilo de apelo discursivo e reformista no qual esses novos partidos se apresentam aos eleitores e se posicionam diante dos partidos políticos tradicionais. Esse tipo de apelo vem sendo utilizado, em maior número, por novas organizações de centro e centro-direita, fundadas por figuras pertencentes aos estratos mais ricos da região ${ }^{58}$. No entanto, após serem eleitos, nenhum dos novos partidos apresentou ideias radicalmente novas ou levou a cabo suas propostas mais populares, com destaque para o fim da imunidade parlamentar como a primeira bandeira a ser esquecida (HAVLIK e HLOUSEK, 2014; HANLEY e SIKK, 2014; BARBOSA, 2016). Dessa forma, suas habilidades políticas ficam confinadas a apenas captar a forte insatisfação pública com aspectos do status quo, inadequadamente tratadas pelos partidos políticos tradicionais e dominantes no cenário político.

Nossa compreensão sobre a abordagem do fenômeno nessa região é de que o populismo foi simplificado a um simples exame de técnicas e estratégias políticas utilizadas para fins de mobilização, somado à interpretação do fenômeno nos velhos moldes das teorias da modernização latino-americanas. Estas teorias (FERREIRA, 2001) abordaram o fenômeno sob um ponto de vista que descreveu o populismo como o governo de um hábil demagogo, encarnado na figura de um líder carismático que manipula as massas para obter seu apoio e votos. As massas, por sua vez, são colocadas em um estado amorfo que a torna ainda incapaz de adquirir consciência de classe, permanecendo em um estágio de fragilidade e fácil dominação pelas retóricas populistas. Com efeito, o conceito de populismo passou a ter seu uso abusado no discurso político e, "de uma forma geral, ao chamar alguém de "populista", as pessoas estão apenas expressando uma avaliação negativa sobre um determinado ator ou agenda política" (SCHMITTER, 2006: p. 1). Em resumo, produziu-se uma literatura com a estereotipação do populismo com um significado que o atrela apenas a um regime de falseamento da verdade sob um ângulo, também, de apropriação entre elites competidoras entre si.

Se, por um lado, construiu-se esse entendimento negativo do populismo, por outro, foram esquecidas suas características intrinsecamente democratizantes que remetem a inclusão dos desejos dos excluídos em seus resultados políticos. Com efeito, produziu-se, no fim, uma abordagem conservadora sobre o assunto:

Populismo é o nome cômodo com que se dissimula a contradição entre legitimidade popular e científica, a dificuldade do governo da ciência para aceitar 
as manifestações da democracia e mesmo a forma mista do governo representativo. Esse nome mascara e ao mesmo tempo revela a grande aspiração da oligarquia: governar sem povo, isto é, sem divisão do povo, governar sem política (RANCIERÈ, 2014: p. 102).

Nosso entendimento sobre o fenômeno do populismo está, em grande parte, alinhado aos trabalhos de Laclau (2005a), Rancière (2014) e Mendonça (2014). Entendemos que o populismo não constitui qualquer tipo de ideologia, mas sim um fenômeno social que resulta de suas políticas reivindicadas em realizações práticas, as quais se traduzem pela inclusão de questões sociais mais urgentes de estratos e vozes excluídas, até então da agenda política, não sendo ele quem emerge após uma "falência das elites", mas sendo suas demandas que, ao se chocar com o modo de governabilidade das elites, quebram sua hegemonia e levam a um momento de negociações com elementos democratizantes e à reconfiguração do espaço público entre o povo e os grupos dominantes desejosos por sua preservação no poder.

Para haver populismo é necessário, antes, que existam estratos sociais organizados e mobilizados em torno de questões sociais importantes que não fazem parte da agenda política ou que foram excluídas desta. É no momento em que há organização social em torno de frustrações comuns (LACLAU, 2005a) $)^{59}$, isto é, sob forma de um mobilizado agrupamento humano com reivindicações sociais, que o fenômeno do populismo começa a tomar a forma necessária para entrar legitimamente nos espaços de conflitos, se tornando político. Entendemos que o populismo, enquanto fenômeno, emerge sempre, ou tem sempre emergido, em um contexto de democratismo que acompanha os avanços nas sociedades que tornam-se mais complexas. A complexidade, por sua vez, se traduz na inclusão, atendimento e aumento das demandas populares e impõe à elite hegemônica a tarefa de reconfigurar a dominação dentro do estado (RANCIERĖ, 2014). A elite dominante, então, pode se encontrar em um estado incapacitado para reorganizar a dominação ou mesmo proceder a uma total recusa de negociação com os valores democráticos, causando uma série de frustrações na população. Com efeito, instala-se uma crise aguda que leva a capitulação da elite e sua substituição por outra elite disposta e capaz de ceder e negociar espaços com a democratização e, assim, reorganizar a dominação.

Esse é o motivo, errôneo para nós, que leva muitos analistas em classificar o populismo apressadamente, tão logo identificam as aludidas técnicas e estratégias discursivas e de mobilização que, no fim, resultam em demagogias de seus arautos. No entanto, devemos notar que estas seguem constructos que são característicos da própria lógica do fenômeno do político em si (SCHMITT, 2009; LACLAU, 2005a), as quais são ferramentas utilizáveis para uso de qualquer partido ou grupo político em competição com outro(s), sem necessariamente constituir um fator de caracterização deste como populista.

Para resultar em fenômeno social que justifique sua existência, o populismo se constitui de técnicas e estratégias do fenômeno do político, pois obedece a mesma lógica que estrutura esse conceito. Realiza-se, então, o corte antagônico notabilizado pelas diferenças e derivações que possam ser extraídas da dicotomia entre amigo versus inimigo (SCHMITT, 2009), o qual passa a dividir a esfera social colocando, de um lado, as demandas populares e, do outro, a institucionalidade. Dessa forma, cria-se um de seus elementos políticos fundamentais, a identidade entre os sem poder (amigos) versus o poder (inimigos). É nesse ponto que se formam as construções discursivas contra o establishment (nós versus eles), com o apelo antiestablishment aparecendo como uma ferramenta dentro da própria lógica da política. Isso, por si só, não constitui um elemento para determinar toda a ocorrência de fenômeno do populismo, se tratando de característica própria e intrínseca da política e de qualquer fenômeno que a tome para justificar sua existência e legitimidade. Para nós, a crítica que se faz ao populismo, ao mesmo tempo que expõe o que há de político neste, oculta o que há de político em si próprio, tornando as análises e o discurso contrapopulista, muitas vezes, um discurso da despolitização de si ou do campo a que pertence:

O populismo não só tem sido degradado, mas também denegrido. Seu rechaço tem sido parte da construção discursiva de certa normalidade, de um universo político asséptico do qual sua lógica perigosa teria que ser excluída ${ }^{60}$. 
Flávio Rodriguês Barbosa

Com efeito, evitar as características democráticas do populismo implica na manutenção de um projeto político que retire as massas da política, substituindo-as por governos cada vez mais compostos por técnicos e gestores teoricamente competentes, uma vez que "trocar a política pela administração tem sido sempre a ideologia conservadora das elites econômicas da América Latina" ${ }^{\prime \prime 1}$. E não foi justamente isso que vimos no projeto do ANO 2011?

No nosso entendimento, ser populista significa incluir, negociar e atender demandas e reivindicações populares na reconfiguração do espaço público. Equivale a pertencer a um fenômeno em movimento e produzir efeitos sociais populares positivos. Trata-se de um momento de inclusão e realização das principais questões sociais na agenda política, algo que ainda está distante das realizações pós-eleitorais dos novos e bem-sucedidos partidos de centro-direita da Europa Central que estudamos nos últimos anos. Chamamos, então, provisoriamente, de organizações ou partidos demagogos (ou o novo com velhos ares) justamente o que os analistas do fenômeno na região centro-europeia vêm chamando indiscriminadamente de populismo. Se os novos partidos de centrodireita não cumprirem suas promessas, se não negociarem uma satisfatória reconfiguração do espaço público, um caminho para a ascensão eleitoral de novos partidos de esquerda que incluam as demandas populares estará pavimentado ${ }^{62}$. A disputa entre os dois lados antiestablishment (nova direita e nova esquerda) deflagrará uma real situação de populismo, sem espaço para o retardamento de negociações sobre a configuração da dominação no espaço público, o que leva inevitavelmente o lado conservador a um maior nível de democratismo nas negociações políticas com relação ao nível inicialmente de abertura desejado, desencadeando, assim, em nossa visão, uma real situação de populismo enquanto fenômeno.

(Recebido para publicação em fevereiro de 2018)

(Reapresentado em junho de 2018)

(Aprovado para publicação em julho de 2018)

\section{Cite este artigo}

BARBOSA, Flávio Rodriguês. Um Debate sobre o Populismo na Europa Central Pós 1989. Revista Estudos Políticos: a publicação semestral do Laboratório de Estudos Hum(e)anos (UFF). Rio de Janeiro, Vol. 9 |N.1, pp. $104-123$, julho de 2018. Disponível em: http://revistaestudospoliticos.com/

\section{Notas}

1. Pois diferente do antiestablishment convencional, este se dirige ferozmente contra os partidos e a política tradicional sem pregar contra a democracia, mas com objetivo de reforça-la com mecanismos de democracia direta (BARBOSA, 2016).

2. São citados pelo autor: Schöpflin (1992); Bútora, Bútorová e Gyarfásová (1994); Vladimir Tismaneanu (1996); Štefan Markus (1997); Erazim Kohák, Melich (1997). 
3. Ver: GIDRON e BONIKOWSKI (2013), os quais fazem referência à América Latina; KALTWASSER e MUDDE (2011), para uma referência da Europa ocidental; enquanto SMILNOV e KRASTEV (2008), KRASTEV, (2007), RUPNIK (2007) e SKOLKAJ (2000) fazem referência à Europa Central.

4. Ver: URBINATI, Nadia (2014). The Populist Power. In: Urbinati, Nadia. Democracy Disfigured. Opinion, Truth and the People. Cambridge, MA/Harvard University Press, 2014, p. 128-170. Ver também da mesma autora: URBINATI, Nadia. (1998). Democracy and Populism. Constellations. International Journal of Critical and Democractic Theory, 1998, vol. 5. p. 110-124.

5. Trata-se da maneira como tais partidos abordam uma versão mercadológica da dicotomia "nós" versus "eles", em uma versão entre o "velho" versus o "novo" na política partidária, onde o elemento velho figura como um "produto gorduroso" pesado ideologicamente e carregado de negatividade, enquanto o novo se apresenta leve e saudável, no melhor estilo de um produto light encontrado em prateleiras de supermercado.

6. Partido Cívico Húngaro.

7. E aqui não apenas figura o centro-europeu, mas também a região dos Bálcãs e do leste, compreendendo muitas das ex-repúblicas do bloco soviético.

8. Lideranças políticas polonesas, tendo feito parte do partido Solidariedade, de Lech Walesa. Fundaram o partido político populista PIS - Prawo i Sprawiedliwość (Lei e Justiça) em 2001.

9. Em 2004 e 2005, Lech Kaczynski, então prefeito de Varsóvia, reprimiu e baniu "A Parada do Orgulho Gay". Em seu discurso, Kaczybski justificou seus atos dizendo não reconhecer os homossexuais como cidadãos poloneses de direitos justificando, também, que o florescimento de uma cultura homossexual na Europa resultaria na morte da cultura heterossexual (Poland's President and Prime Minister Lech and Jaroslav Kacczynski. New Internationalist. 01/04/2007).

10. Última emenda realizada em 2006.

11. Partidos que recebem até $1 \%$ de votos recebem uma compensação do Estado de 30 CZK por cada voto conquistado. Os valores se elevam para aqueles que alcançam 1,5\% da preferência dos eleitores, recebendo do Estado uma compensação de 100 CZK para cada voto obtido. São titulares do auxílio fixo anual os partidos políticos que conquistam pelo menos $3 \%$ de votos para a Câmara dos Deputados. O auxílio por mandato é concedido ao partido se este eleger, pelo menos, um representante para a Câmara dos Deputados, Senado ou para o Conselho da Cidade de Praga (Câmara dos Vereadores). O auxílio básico para quem alcança $3 \%$ dos votos é de $6.000 .000 \mathrm{CZK}$ anuais, valor que é adicionado de 200.000 CZK para cada $0,1 \%$ de votos a mais. $O$ valor se altera até os partidos alcançarem $5 \%$, permanecendo o mesmo para todos aqueles que ultrapassaram essa margem, independente de números. Os partidos recebem 900.000 CZK anuais por cada deputado ou senador 
eleito, e 250.000 anuais para cada vereador eleito para o Conselho da Cidade de Praga.

12. Ver: Barbosa, 2016.

13. Referimo-nos ao Partido Democrata Cívico (ODS), ao Partido Democrata-Cristão (KDU-CSL) e ao Partido Social Democrata (CSSD).

14. Ver: Barbosa, 2016.

15. Fonte: volby.cz.

16. BARBOSA, 2016.

17. 47 de 200 , enquanto os sociais democratas ficaram com apenas três cadeiras a mais (50 de 200). Fonte: volby.cz.

18. Volby.cz.

19. Portal ANO2011 (www.anobudelip.cz) e CEE Identity. (2013). Akce Nespokojených Obcanu, ANO2011 (Action of Dissatisfied Citizens 2011). Institut Pro Evropskou Politiku. National Identity in Central-eastern Europe.

20. "The Rise of 'Babisconi'". ERS. 30/10/2013. Ver também: "Central Europe's Berlusconi?". The Economist, 02/11/2013; e: "'Czech Berlusconi' is the real winner of early elections". Aktualne, 27/10/2013.

21. CEE Identity (2013) e ANO2011. Politický Program (2013).

22. Ibidem. ibid.

23. Ibidem. Ibid.

24. Ibidem. ibid.

25. ANO2011. Volební Program 2013. Disponível em: www.anobudelip.cz e em www.jiine-knihy.cz).

26. Pen Shoen Berland (PSB), famosa pela campanha vitoriosa de Bill Clinton. A PSB já havia trabalhado na República Tcheca em 2006, quando levou os sociais democratas (CSSD) à vitória.

27. Fonte: <www.anobudelip.cz>.

28. Ibidem.

29. Portal ANO 2011, 2013 apud. Prokesová, 2014: 33.

30. Ibidem.

31. (BABIS, 2012). Andrej Babis em atividade blogueira, comentando o "caso Nagy". Fonte: andrejbabis.idnes.cz

32. Portal ANO 2011, 2013c apud. Prokesová, 2014: 33. Babis endereça ao ODS algumas das acusações sofridas sobre a colaboração com a polícia secreta do regime comunista.

33. Ceská Televisá volební superdebata 2013.

34. Ibidem.

35. ANO 2011, Volební Program 2013.

36. Ceská Televisa Volební Superdebata 2013.

37. ANO2011, Volební Program 2013.

38. Ceská Televisa Volební superdebata 2013. Aqui é um momento onde a palavra Lidem possa ter sido empregada como povo, no entanto a mesma também é comumente utilizada para se referir à pessoas.

39. www.anobudelip.cz

40. ERS. 30/10/2013. The Rise of "Babisconi".

41. Financial times. 24/10/2013. Czech billionaire appeals ti Disaffected voters.

42. The New York times. 05/11/2014.

43. Aktualne.cz. 27/10/2012. Stat ma penez jako zelez. Jenze oni to projbou (O Estado tem muito dinheiro. Mas eles o desperdiçam).

44. Ibidem. 
45. Parlament. 16/09/2014. Jem Pravicak com a Socialne Citeni. Ale Nejsem Politik Prisel Jsem z Joneho Sveta (Eu sou direitista, mas eu tenho consciência social. Eu não sou político. Eu vim de um outro mundo).

46. ANO2011 Volební Program 2013.

47. Portal ANO 2011, 2013c Apud. Prokesová, 2014: 36.

48. Um excelente trabalho sobre a imagem de Andrej Babis e seu partido através da mídia tcheca pode ser conferido em: Bradávková, Jana. (2015). Analýza mediálního obsahu v kontextu působení ANO 2011 v politickém systému ČR. Bakalářská práce. Masaryk University. Faculty of Social Studies. Katedra Politologie.

49. Aktualne. 27/10/2013. "Czech Berlusconi" is the real winner of early elections.

50. Government of Czech Republic (www.vlada.cz). 29/01/2014. Coalition Agreement Between the CSSD yes KDU-CSL parties and the ANO movement for the 2013-2017 electoral period.

51. Na grande aquisição de subsídios da UE e no pagamento de menos impostos, comparada a outras empresas. Ver: Echo24. 21/01/2016. Babisu Agrofert Dostava Vic Nez Plati na Danich (A Agrofert, de Babis, obtém mais e paga menos impostos).

52. Politico. European Voice. 09/11/2014. Andrej Babis. Czech Oligarch.

53. Fonte: LUZAR (2014).

54. Volby.cz.

55. Embora declaradamente um partido de centroesquerda, os piratas tchecos concentraram sua campanha com fortes ataques ao establishment e forte retórica anticorrupção, utilizando-se das mesmas fórmulas notabilizadas pelos novatos e bem-sucedidos partidos de centro-direita atrelados a um populismo. Ver: www.pirati.cz.

56. Volby.cz.

57. Volby.cz.

58. Como nos casos de Simeon II, ex-rei da Bulgária; Andrej Babis (ANO 2011), bilionário do setor petroquímico; Tomio Okamura, fundador do ÚSVIT (Alvorecer) e do SPD (Liberdade e Democracia Direta), empresário de sucesso na área de turismo na EuropaCentral; Karel Schwazemberg (TOP 09), membro de uma tradicional família da realeza tcheca; Vit Bárta (Veci Verejné - Assuntos Públicos), proprietário da maior agência de segurança da República Tcheca; Frank Stronach (TEAM Stronach), empresário austríaco e proprietário de diversas empresas do setor automotivo (BARBOSA, 2016).

59. A frustração é o não atendimento de solicitações que podem ser realizadas através de canais institucionais formais. Com o acúmulo de frustrações, estas passam a se articular entre si e geram as reivindicações (LACLAU, 2005a).

60. Entrevista com Ernesto Laclau. Folha de São Paulo. 15/12/2013. O Discreto Charme do Populismo.

61. Ibidem.

62. A mesma previsão é feita por Laclau, em entrevista à Folha de São Paulo. 15/12/2013. 


\section{Bibliografia}

Flávio Rodriguês Barbosa

BARBOSA, Flavio A. Rodrigues. O Teatro das

Representações Trocadas. Corrupção, Ascensão

Antiestablishment e o Partido-empresa de Negócios

na Europa Central Pós 1989. Juiz de Fora: tese de

doutorado. Programa de Pós-graduação em Ciências

Sociais da Universidade Federal de juiz de Fora, 2016.

BARBOSA, Flávio Rodrigues. "Partidos Políticos

Antiestablshment na Europa Central Pós 1989: uma

lógica populista?" Revista Teoria e Pesquisa. Dossiê

Revisitando o Populismo, 2017a, vol.26, no.1, pp.36-

64.

BRADÁVKOVÁ, Jana. Analýza mediálního obsahu v kontextu působení ANO 2011 v politickém systému ČR. Bakalářská práce. Masaryk University. Faculty of Social Studies. Katedra Politologie, 2015.

CANOVAN, M. Taking politics to the people: populism as a ideology of democracy. In: Mény, Y.; Surel, Y.

(Eds.). Democracies and the populist challenges. New York: Palgrave, 2002.

CEE Identity. Akce Nespokojených Obcanu, ANO2011

(Action of Dissatisfied Citizens 2011). Institut Pro

Evropskou Politiku. National Identity in Centraleastern Europe, 2013.

DVORÁKOVÁ, Vladimira. Corruption in Post-communist

States. Causes and Impacts. Graduate Conference on Corruption and Anti-Corruption. Brighton: University of Sussex, 2015.

FERREIRA, Jorge. O populismo e sua história: debate e crítica. Rio de Janeiro: Civilização Brasileira, 2001.

GIDRON, Noam; BONIKOWSKI, Bart. Varieties of Populism: Literature Review and Research Agenda. Weatherhead Center for International Affairs. Harvard University, 2013.

GRYSMALA-BUSSE, Anna. Rebuilding Leviathan: Party Competition and the State Exploitation in PostCommunist Democracies. Cambridge: Cambridge Uinversity Press, 2007.

HANLEY, Sean; SIKK, Alan. Economy, corruption or floating voters? Explaining the breakthroughs of antiestablishment reform parties in Eastern Europe. The EU's FP7 ANTICORRP Project, 2014.

HAUGTON, Tim. "Parties, Patronage and the PosCommunist State". Comparative European Politics, 2008, no 6. Pg. 486-500.

HAVLIK, Vlatismil; HLOUSEK, Vít. Dr. Jekyll and Mr. Hyde: The Story of the Populist Public Affairs Party in Czech Republic. Perspectives on European Politics and Society. Brno: Taylor \& Francis, 2014.

HELLMANN Joel; JONES, Geraint; KAUFFMANN, Daniel. "Seize the State, Seize the Day". State Capture, Corruption and Influence in Transition. The World Bank Institute. World Bank, 2000.

HOFSTADTER, Richard. "The Paranoid Style in American Politics". Harper's Magazine, 1964, pp. 7786. 
JANSEN, R. S. Populist mobilization: a new theoretical approach to populism. Sociological Theory, v. 2, n. 29, p. 75-96, 2011.

KRASTEV. "The New Europe: Respectable Populism, Clockwork Liberalism". Open Democracy Journal. Free Thinking for the World, 2006.

KRASTEV, Ivan. "The Strange Death of Liberal Consensus". Journal of Democracy, vol. 18, no. 4. pp. 56-63, 2007.

LACLAU, Ernesto. "O Discreto Charme do Populismo". Entrevista. Folha de São Paulo. 15/12/2013.

LACLAU, Ernesto. La Razón Populista. Buenos Aires/Mexico: FCE, 2005a.

LACLAU, Ernesto. "Ernesto Laclau Defende o Populismo Latino-americano para Assegurar a Participação Política". Entrevista concedida à Daniel de Mendonça, publicado em: Zero Hora: 12/04/2014. LUZAR, Lukás. (2014). Analýza volební kampaně ve volbách do PS PČR v roce 2013: prípadová studie hnutí ANO 2011. Bakalářská práce. Univerzitá Palackehó v Olomouci. Filozofická fakulta. Katedra politologie a evropských studií.

MENDONÇA, Daniel de Populismo como vontade de democracia. Colombia International, no. 82. pp. 59, 2014.

MUDDE, Cas. Populist Radical Parties in Europe. New York: Cambridge University Press, 2007.

MUDDE, Cas; KALTWASSER, Cristóbal. Voices of the People. Populism in Europe and Latin America Compared. The Helen Kellog Center for International Researches. Working Paper no. 378, 2011.

MUDDE, Cas. (2013). "Three Decades of Populism Radical Parties in Western Europe: so what?" European Journal of Political Research, no. 59. pp. 119, 2013.

MUSILOVÁ, Marketa. Politická strana Věci veřejné pohledem konceptu populismu. Bachelor Thesis. Masarykova Univerzita v Brne. Fakulta Sociálních Studií. Katedra Politologie, 2011.

PROKESOVÁ, Alzbeta. ANO2011 Jako Priklad Populistické Strany? Bakalásrská Práce. Masarykova Univerzita v Brne, Fakulta Sociálních. Katedra Politologie, 2014.

RANCIÈREe, Jacques. O Ódio à Democracia. São Paulo: Boitempo, 2014.

RUPNIK, Jaques. (2007). From Democracy Fatigue to Populist Backlash. Journal of Democracy. Vol. 18, n. 4. SALAMANCA, Luis Jorge Garay (Org.). La Captura e la Reconfiguración del Estado em Colombia. Bogotá: Fundação METODO, 2008.

SCHMMITT, Carl. O Conceito do Político. Teoria do Partisan. Belo Horizonte: Del Rey, 2009.

SCHMITTER, Phillip. A Balance Sheet of the Vices and Virtus of "Populisms. European University Institute \& Central Europe University, 2006. 
SKOLKAY, Andrej. "Populism in Central Eastern Europe". In: Thinking Fundamentals, IWM Junior Visiting Fellows Conferences, vol. 9, 2000.

SMILNOV, Daniel; KRASTEV, Ivan. "The Rise of Populism in Eastern Europe: Policy Paper". In: Meseznikov, G.; Gyarfasova, O; Smilnov, D. (eds). Bratislava: Institute for Public Affairs, 2008.

URBINATI, Nadia. (1998). "Democracy and Populism. Constellations". International Journal of Critical and Democractic Theory, 1998, vol. 5. pp. 110-124. URBINATI, Nadia. "The Populist Power". In: Urbinati, Nadia. Democracy Disfigured. Opiniom, Truth and the People. Cambridge, MA/Harvard University Press, 2014 p. $128-170$.

Outras Referências

Aktualne.cz. 27/10/2012. Stat ma penez jako zelez. Jenze oni to projbou.

Aktualne, 27/10/2013. "'Czech Berlusconi' is the real winner of early elections".

Echo24. 21/01/2016. Babisu Agrofert Dostava Vic Nez Plati na Danich.

ERS. 30/10/2013. "The Rise of 'Babisconi"'.

Financial times. 24/10/2013. Czech billionaire appeals ti Disaffected voters.

New Internationalist. 01/04/2007. Poland's President and Prime Minister Lech and Jaroslav Kacczynski.

Politico. European Voice. 09/11/2014. Andrej Babis. Czech Oligarch.

Parlament. 16/09/2014. Jem Pravicak com a Socialne Citeni. Ale Nejsem Politik Prisel Jsem z Joneho Sveta.

The Economist, 02/11/2013, "Central Europe's

Berlusconi?".

The New York times. 05/11/2014.

\section{Sites}

www.anobudelip.cz

Volby.cz.

\section{Documentos}

ANO2011, Volební Program 2013.

Ceská Televisa Volební superdebata 2013.

Government of Czech Republic (www.vlada.cz). 29/01/2014. Coalition Agreement Between the CSSD yes KDU-CSL parties and the ANO movement for the 2013-2017 electoral period.

The Constitution of Czech Republic. www.hrad.cz 